\title{
Low Temperature Ni-Al Ohmic Contacts to P-TYPE 4H-SiC Using Semi-Salicide Processing
}

\section{Mattias Ekström ${ }^{1, a^{*}}$, Shuoben Hou $^{1, b}$, Hossein Elahipanah ${ }^{1, \mathrm{c}}$, Arash Salemi $^{1, \mathrm{~d}}$, Mikael Östling ${ }^{1, e}$, Carl-Mikael Zetterling ${ }^{1, f}$}

\author{
${ }^{1}$ KTH Royal Institute of Technology, School of ICT, Department of Electronics, 16440 Kista, \\ Electrum 229, Sweden \\ a*mekstr@kth.se (corresponding author), bshuoben@kth.se, chosseine@kth.se, dsalemi@kth.se, \\ emostling@kth.se, 'bellman@kth.se
}

Keywords: Ni-Al, p-type ohmic contact, rapid thermal processing (RTP), silicon carbide $(4 \mathrm{H}-\mathrm{SiC})$, transfer length method (TLM)

\begin{abstract}
Most semiconductor devices require low-resistance ohmic contact to p-type doped regions. In this work, we present a semi-salicide process that forms low-resistance contacts $\left(\sim 10^{-4} \Omega \mathrm{cm}^{2}\right)$ to epitaxially grown p-type $\left(>5 \times 10^{18} \mathrm{~cm}^{-3}\right) 4 \mathrm{H}-\mathrm{SiC}$ at temperatures as low as $600{ }^{\circ} \mathrm{C}$ using rapid thermal processing (RTP). The first step is to self-align the nickel silicide $\left(\mathrm{Ni}_{2} \mathrm{Si}\right)$ at $600{ }^{\circ} \mathrm{C}$. The second step is to deposit aluminium on top of the silicide, pattern it and then perform a second annealing step in the range $500{ }^{\circ} \mathrm{C}$ to $700{ }^{\circ} \mathrm{C}$.
\end{abstract}

\section{Introduction}

Both bipolar junction transistors (BJTs) and P-channel metal-oxide-semiconductor field-effect transistors (PMOSs) benefit from low-resistance p-type ohmic contacts, as the contact resistance is a parasitic resistance for these devices. It is challenging to form low-resistance contacts to p-type $4 \mathrm{H}-\mathrm{SiC}$ due to the combination of lack of suitable metal work function $(\sim 7 \mathrm{eV})$, partial Fermi level pinning [1] and technological issues in achieving p-type doping higher than $10^{19} \mathrm{~cm}^{-3}$.

Several different p-type contacts have been proposed and investigated, such as $\mathrm{Ni}-\mathrm{Al}$ [2-5], NiTi-Al [2, 6-8], Ge-Ti-Al [9], Ti-Al [4, 10, 11], epitaxially grown MAX-phase $\mathrm{Ti}_{3} \mathrm{SiC}_{2}$ [12], phase segregation annealed co-sputtered Pt-Ti [13] and pure titanium [14]. The necessary annealing temperatures and times vary for different contacts. The contacts typically require annealing temperatures up to $1000{ }^{\circ} \mathrm{C}$ to form low-resistance contacts $\left(\sim 10^{-4} \Omega \mathrm{cm}^{2}\right)$, with the exceptions of Ge-Ti-Al $\left(600{ }^{\circ} \mathrm{C}\right.$, ultra-high vacuum anneal for $\left.1800 \mathrm{~s}\right)$ [9], titanium $\left(700{ }^{\circ} \mathrm{C}\right.$, surface recrystallization as $3 \mathrm{C}-\mathrm{SiC}$ after high-dose ion-implantation, contact resistivity higher than $10^{-3} \Omega \mathrm{cm}^{2}$ ) [14], and Ni-Ti-Al (800 ${ }^{\circ} \mathrm{C}$ using rapid thermal processing (RTP), narrow temperature window) [6-8]. Of the cited articles [2-14], all except [12-14] explicitly state that evaporation and lift-off (LO) is used to pattern the contact stack, which is unsuitable for volume production.

In this work, we present a LO free/semi-salicide process for fabricating low-resistance Ni-Al contacts to p-type $4 \mathrm{H}-\mathrm{SiC}$. The process employs a first step of nickel salicide (Elahipanah et al. [15]) and a second step of Al sputtering, patterning and RTP (400 ${ }^{\circ} \mathrm{C}$ to $\left.700{ }^{\circ} \mathrm{C}\right)$. The contact resistivity and composition are then measured and discussed.

\section{Experimental}

Two $100 \mathrm{~mm} 4 \mathrm{H}-\mathrm{SiC}(0001)$ wafers with $4^{\circ}$ off-axis cut were used in this experiment. The epitaxy was grown on the Si-face by Norstel [16] and was, from top to bottom, $\mathrm{P}^{+}\left(0.2 \mu \mathrm{m},>5 \times 10^{18} \mathrm{~cm}^{-3}\right) /$ $\mathrm{N}^{-}\left(0.8 \mu \mathrm{m}, 1 \times 10^{16} \mathrm{~cm}^{-3}\right) / \mathrm{P}^{+}\left(1 \mu \mathrm{m}, 5 \times 10^{18} \mathrm{~cm}^{-3}\right) / \mathrm{N}^{+}$-substrate. The top $\mathrm{P}^{+}$-layer was used to form contacts. One wafer was diced into $10 \mathrm{~mm} \times 10 \mathrm{~mm}$ pieces for process development, and one wafer was used to demonstrate a wafer-scale process. Transfer length method (TLM) structures of the same dimensions $(200 \mu \mathrm{m}$ width and $100 \mu \mathrm{m}$ length, separation distances 5, 10, 15, 20 and $25 \mu \mathrm{m})$ were fabricated on both pieces and wafer. 
The TLM-mesas were etched by magnetically enhanced reactive ion etching (MERIE). Etch damage was removed by sacrificial dry oxidation. The surface was passivated by a deposited oxide, followed by a $\mathrm{N}_{2} \mathrm{O}$-based passivation anneal at $1100{ }^{\circ} \mathrm{C}$. The oxide is opened by MERIE to allow contact formation. The oxide etch uses $\mathrm{CF}_{4} / \mathrm{CHF}_{3} / \mathrm{Ar}$ chemistry which etches $\mathrm{SiO}_{2}$ selectively to $\mathrm{SiC}$. No significant amount of $\mathrm{SiC}$ is removed by the etch.

The nickel was self-aligned as proposed by Elahipanah et al. [15]. A nominal $10 \mathrm{~nm}$ Ni-film was deposited by magnetron sputtering. The sample was in-situ cleaned prior to metal deposition by back-sputtering a nominal $7 \mathrm{~nm}$ of $\mathrm{SiO}_{2}$. The silicidation-step is performed in a RTP system with optical pyrometer at $600{ }^{\circ} \mathrm{C}$ for $60 \mathrm{~s}, \mathrm{~N}_{2}$ ambient. The unreacted metal was stripped by Piranha (3:1 $\left.\mathrm{H}_{2} \mathrm{SO}_{4}: \mathrm{H}_{2} \mathrm{O}_{2}\right)$.

A nominal $90 \mathrm{~nm}$ Al-film was deposited by magnetron sputtering on top of the silicide. The thickness was selected to ensure that the $\mathrm{Al} / \mathrm{Ni}$ ratio exceeds $80 \%$ atomic concentration of aluminium, which has been found to reduce the resistivity and formation of $\mathrm{Al}_{4} \mathrm{C}_{3}$ becomes favorable $[2,3]$. The film was patterned by standard optical lithography and etched by reactive ion etching (RIE) using $\mathrm{Cl}_{2}$ and $\mathrm{BCl}_{3}$. The silicide/Al-stack was alloyed using the RTP system. 6 pieces were annealed in the temperature range from $400{ }^{\circ} \mathrm{C}$ to $700{ }^{\circ} \mathrm{C}$ for $60 \mathrm{~s}$ in $\mathrm{N}_{2}$ to determine the temperature window. The wafer was annealed at $600{ }^{\circ} \mathrm{C}$, which was selected to maximise the temperature margins based on the results from the experiments on pieces. The time dependence for formation was not investigated, due to a pending upgrade of the RTP-system.

The pieces and 5 TLM sets on the wafer were measured after contact formation by directly probing the contacts. The wafer was further processed by $\mathrm{SiO}_{2}$ deposition, via opening (MERIE and $10 \mathrm{~s}$ spraying of diluted $\mathrm{HF}$ ) and TiW/Al/TiW deposition/patterning. The contact resistivity of the TLM-structures on the wafer was mapped after the metallization.

\section{Results and Discussion}

Unlike the conventional $\mathrm{Ni}-\mathrm{Al}$ contact that requires anneals up to $1000{ }^{\circ} \mathrm{C}$ [2-5], the semi-salicide processed contacts only require that the second-step anneal is higher than $500{ }^{\circ} \mathrm{C}$ to become ohmic (upper limit not determined). The samples annealed at $400{ }^{\circ} \mathrm{C}$ and $450{ }^{\circ} \mathrm{C}$ showed rectifying behavior. The contacts became ohmic at around $500{ }^{\circ} \mathrm{C}$, and the resistivity decreased with temperature. It should be noted that the temperature window for ohmic contact formation is wide, which gives good processing margins. For temperatures lower than $650{ }^{\circ} \mathrm{C}$, the aluminium should stay solid - thus solid-state reactions may drive the contact formation. For the conventional Ni-Al contacts, the $\mathrm{Ni}-\mathrm{Al}$ can form a liquid-phase under equilibrium conditions at $1000{ }^{\circ} \mathrm{C}$. As such, the chemistry may be different for the conventional Ni-Al contacts and these semi-salicide Ni-Al contacts. A hypothesis is that the SiC-Ni-Al net-reaction is more efficient by breaking it up into two efficient steps instead of having one inefficient step. When separated in two steps, the first step is an efficient $\mathrm{SiC}-\mathrm{Ni}$ reaction, which forms $\mathrm{Ni}_{2} \mathrm{Si}$ with carbon precipitates, and the second step is an efficient $\mathrm{Ni}_{2} \mathrm{Si}$-Al step, which forms $\mathrm{Al}_{4} \mathrm{C}_{3}$ (from the carbon precipitates) and $\mathrm{AlNi}_{\mathrm{x}}$. When done in one step, the SiC-Ni-Al reaction may be dominated by the Ni-Al reaction instead of $\mathrm{SiC}-\mathrm{Ni} /$ $\mathrm{SiC}-\mathrm{Al}$, thus making the process inefficient.

The resistance was determined by measuring voltage when sourcing $\pm 1 \mu \mathrm{A}$. The leakage current was about $2 \mathrm{nA}$. All TLM-structures on the wafer measured after metallization show ohmic behavior and can be fitted to the TLM-model (see Fig. 1), although there is a considerable spread in contact resistivity values. As shown in Fig. 2, about $97 \%$ of the dies have a contact resistivity below $10 \times 10^{-4} \Omega \mathrm{cm}^{2}$. The average wafer contact resistivity and standard deviation are $6 \times 10^{-4} \Omega \mathrm{cm}^{2}$ and $1.5 \times 10^{-4} \Omega \mathrm{cm}^{2}$, respectively (degree of non-uniformity is $25 \%$ ).

The contacts appear to degrade at some point between contact formation and metallization. The 5 sampled TLM sets gave an average $2 \times 10^{-4} \Omega \mathrm{cm}^{2}\left(\right.$ range $\left.0.5 \times 10^{-4} \Omega \mathrm{cm}^{2}\right)$ before metallization and an average $5 \times 10^{-4} \Omega \mathrm{cm}^{2}$ (range $2 \times 10^{-4} \Omega \mathrm{cm}^{2}$ ) after metallization. It is likely that HF is detrimental for the contacts. 

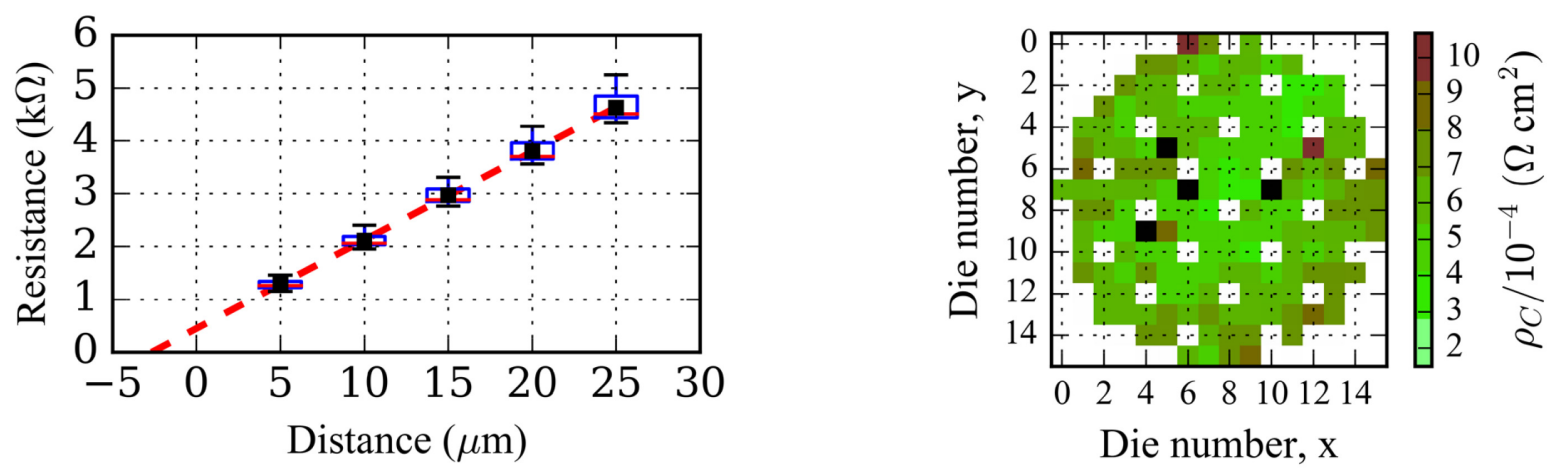

Figure 1. Box plot of TLM-structures on the Figure 2. Wafer map of contact resistivity. White wafer after metallization. The whiskers represent squares represent the absence of measurement the range of measured resistance values. The (either outside of wafer or an excluded die), dashed line represent the wafer averaged black squares are dies with resistivity parameters. $>10^{-3} \Omega \mathrm{cm}^{2} .24$ dies were part of another experiment and were excluded.

The contacts were studied structurally by scanning electron microscopy and transmission electron microscopy (SEM and TEM). Fig. 3 is a SEM image of a TLM contact from the wafer. The contact does not cover the contact hole, as was drawn in the lithography. The contact appears to densify during the alloying. The contact surface is non-uniform and composed of two distinct types of regions (appears as dark or bright areas). Fig. 4 is a TEM image from a TLM contact on one of the pieces. Energy-dispersive x-ray spectroscopy (EDS) and electron energy loss spectroscopy (EELS) identifies the contact as being composed of $\mathrm{Al}_{4} \mathrm{C}_{3}, \mathrm{AlNi}_{\mathrm{x}}$ and $\mathrm{AlO}_{\mathrm{x}}$.
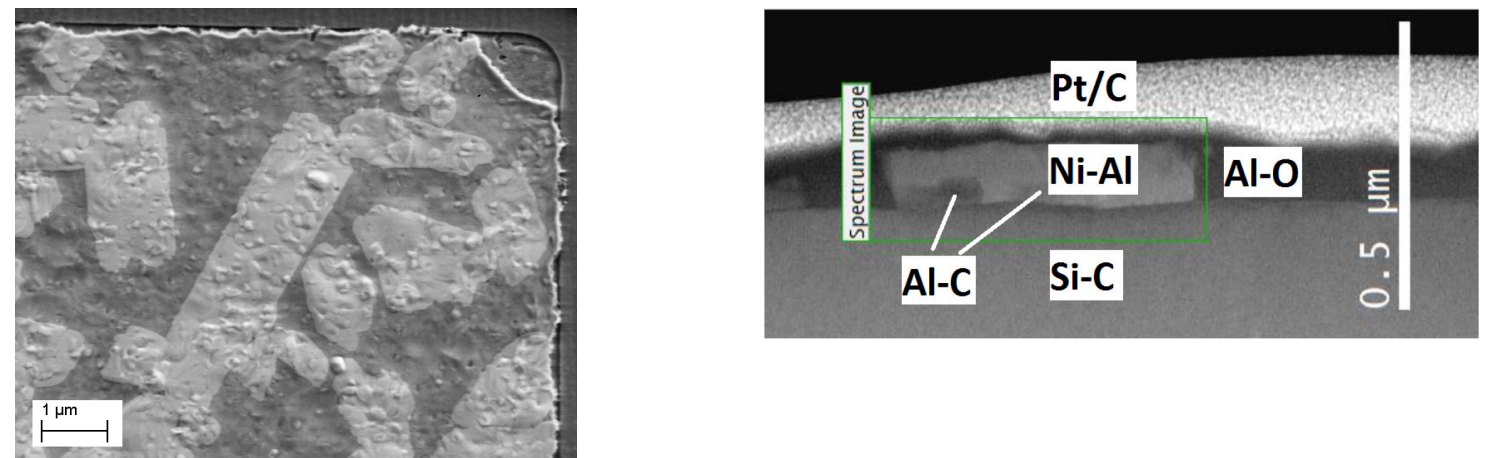

Figure 3. SEM image of the corner of a contact Figure 4. TEM image of a contact (piece). (wafer), after contact formation. Two types of Spectrum analysis by EDS and EELS identifies regions are identified (dark/bright), indicating a Ni-Al, Al-C and Al-O. EDS and EELS only non-uniform contact. EDS identifies that the identify the composition, not phase. $\mathrm{The} \mathrm{Al}_{4} \mathrm{C}_{3}-$ bright areas contain more $\mathrm{Ni}$ than the dark phase is assumed based on previous results areas. $[2,3]$.

\section{Summary}

In this work, we have presented a low-temperature $\mathrm{Ni}-\mathrm{Al}$ ohmic contact process to p-type $4 \mathrm{H}$-SiC. The Ni is self-aligned, followed by alloying the silicide with Al. The temperature window for ohmic contact formation of the second anneal step is wide, $500{ }^{\circ} \mathrm{C}-700{ }^{\circ} \mathrm{C}$. The process was demonstrated on wafer-scale, with 166 measured TLM structures. The average wafer contact resistivity and standard deviation are $6 \times 10^{-4} \Omega \mathrm{cm}^{2}$ and $1.5 \times 10^{-4} \Omega \mathrm{cm}^{2}$, respectively. The contact resistivity degrades on exposure to diluted HF. The contacts are structurally composed of $\mathrm{AlNi}_{\mathrm{x}}$ and $\mathrm{Al}_{4} \mathrm{C}_{3}$, and have a patchy texture. The proposed contact process offers flexibility (compatible with both evaporation/LO and sputtering/etching), low thermal budget (RTP at $600{ }^{\circ} \mathrm{C}$ ) and decent contact resistivity $\left(\sim 10^{-4} \Omega \mathrm{cm}^{2}\right)$. 


\section{Acknowledgement}

The authors thank the Knut and Alice Wallenberg Foundation for funding this research as a part of the Working on Venus project. Fredrik Gustavsson is acknowledged for performing the TEM.

\section{References}

[1] S.-K. Lee, C.-M. Zetterling, M. Östling, Schottky Barrier Height Dependence on the Metal Work Function for p-type 4H-Silicon Carbide, J. Electron. Mater. 30 (2001) 242-246.

[2] R. Konishi, R. Yasukochi, O. Nakatsuka, Y. Koide, M. Moriyama, M. Murakami, Development of $\mathrm{Ni} / \mathrm{Al}$ and $\mathrm{Ni} / \mathrm{Ti} / \mathrm{Al}$ ohmic contact materials for p-type 4H-SiC, Mater. Sci. Eng. B 98 (2003) 286-293.

[3] H. Vang, M. Lazar, P. Brosselard, C. Raynaud, R. Cremillieu, J.-L. Leclercq, J.-M. Bluet, S. Scharnholz, D. Planson, Ni-Al ohmic contact to p-type 4H-SiC, Superlattices Microstruct. 40 (2006) 626-631.

[4] M. R. Jennings, A. Pérez-Tomás, M. Davies, D. Walker, L. Zhu, P. Losee, W. Huang, S. Balachandran, O. J. Guy, J. A. Covington, T. P. Chow, P. A. Mawby, Analysis of Al/Ti, Al/Ni multiple and triple layer contacts to p-type 4H-SiC, Solid-State Electron. 51 (2007) 797-801.

[5] K. Ito, T. Onishi, H. Takeda, K. Kohama, S. Tsukimoto, M. Konno, Y. Suzuki, M. Murakami, Simultaneous Formation of Ni/Al Ohmic Contacts to Both $n$ - and $p$-Type $4 \mathrm{H}-\mathrm{SiC}$, J. Electron. Mater. 37 (2008) 1674-1680.

[6] K. Smedfors, L. Lanni, M. Östling, C.-M. Zetterling, Characterization of Ohmic Ni/Ti/Al and Ni Contacts to $4 \mathrm{H}-\mathrm{SiC}$ from $-40^{\circ} \mathrm{C}$ to $500^{\circ} \mathrm{C}$, Mater. Sci. Forum 778-780 (2014) 681-684.

[7] F. Laariedh, M. Lazar, P. Cremillieu, J. Penuelas, J.-L. Leclercq, D. Planson, The role of nickel and titanium in the formation of ohmic contacts to p-type 4H-SiC, Semicond. Sci. Technol. 28 (2013) 045007-1 - 045007-6.

[8] H. Yu, X. Zhang, H. Shen, Y. Tang, Y. Bai, Y. Wu, K. Liu, X. Liu, Thermal stability of Ni/Ti/A1 ohmic contacts to $p$-type 4H-SiC, J. Appl. Phys. 117 (2015) 025703-1 - 025703-8.

[9] S. Tsukimoto, T. Sakai, M. Murakami, Electrical properties and microstructure of ternary Ge/Ti/Al ohmic contacts to p-type 4H-SiC, J. Appl. Phys. 96 (2004) 4976-4981.

[10] O. Nakatsuka, T. Takei, Y. Koide, M. Murakami, Low Resistance TiAl Ohmic Contacts with Multi-Layered Structure for p-Type 4H-SiC, Mater. Trans 43 (2002) 1684-1688.

[11] M. Vivona, G. Greco, R. Lo Nigro, C. Bongiorno, F. Roccaforte, Ti/Al/W Ohmic contacts to p-type implanted 4H-SiC, J. Appl. Phys. 118 (2015) 035705-1 - 035705-7.

[12] K. Buchholt, R. Ghandi, M. Domeij, C.-M. Zetterling, J. Lu, P. Eklund, L. Hultman, A. Lloyd Spetz, Ohmic contact properties of magnetron sputtered $\mathrm{Ti}_{3} \mathrm{SiC}_{2}$ on $n$ - and $p$-type $4 \mathrm{H}$-silicon carbide, Appl. Phys. Lett. 98 (2011) 042108-1 - 042108-3.

[13] R. S. Okojie, D. Lukco, Simultaneous ohmic contacts to $p$ - and $n$-type $4 \mathrm{H}$-SiC by phase segregation annealing of co-sputtered Pt-Ti, J. Appl. Phys. 120 (2016) 215301-1 - 215301-11.

[14] H. Shimizu, A. Shima, Y. Shimamoto, N. Iwamuro, Ohmic contact on n- and p-type ionimplanted $4 \mathrm{H}-\mathrm{SiC}$ with low-temperature metallization process for SiC MOSFETs, Jpn. J. Appl. Phys. 56 (2017) 04CR15-1 - 04CR15-6.

[15] H. Elahipanah, A. Asadollahi, M. Ekström, A. Salemi, C.-M. Zetterling, M. Östling, A WaferScale Ni-Salicide Contact Technology on n-Type 4H-SiC, ECS J. Solid State Sci. Technology 6 (2017) 197-200.

[16] Norstel AB, Box 734, 60116 Norrköping, Sweden. Webpage: www.norstel.com 